\title{
Social involvement and development as a response to the campus student culture
}

\author{
Min Yang • Albert Wai Lap Chau
}

Received: 10 July 2010/Revised: 12 November 2010/Accepted: 14 January 2011/Published online: 24 February 2011

(C) The Author(s) 2011. This article is published with open access at Springerlink.com

\begin{abstract}
Given the widely accepted notion of whole person education in Confucian societies such as Hong Kong, Mainland China and Singapore, it is surprising that research literature originated in these societies pays little attention to how students learn and develop through out-ofclass experiences at university. There is little research evidence on how the prevailing culture among student social communities (residential halls and student societies/ clubs) influences students' social involvement and development. This paper examines 42 Chinese students' social experiences and development during their freshman year at a Hong Kong university. The majority of them were intensively involved in out-of-class activities. Their active social involvement was both a response to the culture of student communities and a conscious choice about social experiences at university. As a result, the students attained development in four dimensions: (1) the social competences of interpersonal and collaboration skills and new friendships; (2) the practical competences of time management, organisation, negotiation, decision making and leadership; (3) the intellectual competences of openmindedness and independent judgment; and (4) the personal competences of self- responsibility and self-confidence. Educational implications are discussed towards the end of the paper on supporting and advising students
\end{abstract}

\section{Yang $(\bowtie)$}

Centre for the Enhancement of Teaching and Learning, The University of Hong Kong, Room 300, Run Run Shaw Building, Main Campus, Pok Fu Lam Road, Hong Kong, People's Republic of China

e-mail: myangmin@hkucc.hku.hk

A. W. L. Chau

Department of Psychology, The University of Hong Kong, Hong Kong, People's Republic of China regarding social involvement, particularly during the first year of university.

Keywords Whole person education .

Social involvement · Development outcomes .

Out-of-class experiences · Student communities ·

Student culture

\section{Introduction}

The first year of undergraduate education is a stage in which students establish new habits, values, behaviours and relationships that would profoundly influence their development and success at university (Tinto 1993; Yorke and Longden 2007). It is also a critical transitional phase in which students become integrated into the academic (faculties and departments) and social (residential halls and student societies) communities (Tinto 1993).

A holistic understanding of student social experience at university would require investigation into student experiences in both academic (Kember and Lee et al. 2001) and social communities (Astin 1985; Tinto 1993; Pascarella and Terenzini 2005). Out-of-class experiences take place largely in student social communities and are influenced by the student culture-the beliefs, values and patterns of behaviour shared by members of the student communities (Tinto 1993). Yet, few studies have been concerned with the role of student culture in student social experience and development (Arboleda et al. 2003).

Since most existing studies on social experience at university have been undertaken in Western contexts (Harvey et al. 2006), we know little about how university students approach social experiences in Confucian societies (Macao, Singapore, Taiwan, Hong Kong, Mainland 
China and other Asian societies influenced by Confucian culture). This contrasts with the substantial body of research into student learning in these societies, which suggests that the learning culture among Chinese/Asian students values effortful learning, respect for teachers and family/communal interests (Watkins and Biggs 2001).

The minimal attention to social experiences is at odds with the notion of whole person education widely accepted in Confucian societies (Yee 2001). The notion entails the facilitation of students' balanced development in the intellectual, moral, physical and aesthetic dimensions. To grasp a broad picture of how students grow as whole persons at university, it is highly important to investigate students' social experiences and associated outcomes.

This paper was the outcome of our effort to pursue the research agenda delineated above. We drew on data from focus groups with 42 Chinese students conducted in fall 2007 at a research- and teaching-intensive university in Hong Kong to explore the research question: How did the student culture influence the Chinese students' social involvement and development during their first year of university? The question was explored from a phenomenological perspective to grasp the nature and structure of the Chinese students' social involvement and development.

The focus groups were part of a larger research project on first-year experience that provided evidence for the new four-year undergraduate curriculum reform of the university. The reform is in turn part of the ongoing curriculum reform promoted by the Hong Kong Special Administrative Region (HKSAR) government. First-year experience is identified as one of the focal points in strengthening the new undergraduate curriculum for students' whole person education (UGC 2010).

In the rest of the paper, we first review theories and existing studies relating to social involvement and development at university that assisted us in exploring the research question. Then, we describe methodological issues that encompass the population and site of the research, and data collection and analysis processes guided by the phenomenological perspective. We then present the results of data analysis on the Chinese students' social involvement and development. Educational implications of the findings are discussed towards the end of the paper.

\section{Social involvement and development at university}

To explore the research question, we have reviewed theories and existing studies relevant to students' social experiences and development in Western and Chinese contexts. In the review, particular attention has been given to exploring how the theories and existing research evidence might be relevant to the social-cultural context of Confucian societies.

Social integration into communities at university

According to Tinto (1993), the institutional environment is a system composed of intellectual/academic (departments and faculties) and social communities (halls of residents, and various student societies, clubs and associations). Each community has its specific sub-culture, which includes normative attitudes, values, accepted style of communication and behaviour, and worldview. Individuals' social integration is facilitated by a sense of congruence with at least one of these communities at university. Social integration in turn would promote learning and development.

Consistent with Astin's (1985) involvement theory and Pace's (1984) theory of quality of student effort, Tinto's concept of social integration suggests that greater level of involvement would increase learning and development. Further, the communities provide individuals with opportunities to mix and interact with students and staff members from different backgrounds and holding different beliefs. Such diverse social situation affords students with opportunities of developing the ability of critical thinking and an open mind. Individuals do not simply adapt passively to the institutional environment, but would play an active role in forming personal goals and choosing future educational activities.

The concept of social integration usefully analyses the institution environmental influences on individuals' social experiences and growth. Similar models of institutional environment include Sterns' (1970) theory of institutional express (general institutional tendencies that direct individuals' behaviours and actions) and the theory of campus culture (climate of the institution as reflected in the traditions, history, mission statements, rules and stories shared by members) used by Kuh and Hall (1993).

The concepts of social integration, institutional express and campus culture provide us with important insights into how the Chinese students' development as a result of interaction with the student culture in student communities. To gain a holistic understanding of the students' social experiences and development, it is critical to view the student communities as an integral part of the larger social fabric, which in this study is the wider Confucian society. For instance, individuals in Confucian societies are expected to attain social harmony through compliance to authoritative or dominant views and through active contribution to collective/group goals (Bond and Smith 1996; Kember and Gow 1991; Watkins and Biggs 1996, 2001). In order to ground this study in the specific social-cultural context experienced by the students, it would be necessary to take note of how such Asian or Confucian values 
influenced students' social participation and ensuing development.

Students as active participants at university

In conceptualising students' social experiences and development, there is a need to make an even stronger case of students' proactive role than Tinto (1993) did. The concept of students as active participants at university is of particular relevance in this regard (Dewey 1938; McInnis 2001). It advocates that educational experiences should be designed to guide students in taking an active part in making decisions about their own education.

This concept was adopted by McInnis et al. (1995) as a theoretical framework for a national study on Australian first-year students' experience (McInnis 2001). Based upon the sociological studies on adolescent education, the concept suggests that by making some decisions about their curriculum and learning paths, students can play a proactive role in their undergraduate education.

To play such a proactive role, students need to develop the abilities of independent thinking and effective learning, which requires a 'cultivating climate' where teacher guidance and demands by university are balanced against student choices/preferences and peer collaboration (McInnis 2001). This idea echoes with Dewey's (1938) theory of experiential learning, which suggests that educational experiences should be arranged as opportunities for students to take responsibilities for their actions, such that the time spent at schooland at university - contributes not only to students' preparation for life but also to their active participation in society.

We would argue that taking a proactive role in social and academic spheres of university education constitutes an important facet to Chinese students' whole personal development. Some educators lament that Chinese students from Confucian societies are passive individuals. Yet, existing research literature suggests that Chinese students do engage actively in their academic studies (Kember et al. 2001; Watkins and Biggs 2001) and seek active participation in meaningful social activities ( $\mathrm{Ng} 2009)$ when put in facilitative learning environments. In order to gain insights into students' whole person development, it would be important for researchers in Confucian societies to investigate the extent to which Chinese and other Asian students actively take part in the university community and its sub-communities. New knowledge gained in this respect would be indispensible for educators in Asian and Western contexts to provide support and guidance for Chinese/Asian students.

\section{Existing studies in Western countries}

The impact of involvement at university on students' development has been a focus in Australian and UK national studies on first-year experience (Krause and Hartley 2005; Yorke and Longden 2007). Academic/social engagement has also been investigated in the American and Australasian (Australia and New Zealand) Surveys of Student Engagement (Coates et al. 2008). These studies reported social interactions at university as positively associated with social, personal, ethical and interpersonal capabilities, satisfaction and sense of belonging (Krause and Hartley 2005; Kuh 1993, 1995). Optimal development was reported as linking to the following experiences: living in on-campus residence, holding office in a student society/association, diversity in student population and part-time employment on campus.

Based on 149 interviews with seniors, Kuh developed an outcomes taxonomy encompassing five categories: (1) personal competence (self-awareness, autonomy, confidence, social competence and sense of purpose); (2) cognitive complexity (reflective judgement and knowledge application); (3) knowledge and academic skills (knowledge and academic skills); (4) practical competence (practical competence and vocational competence); and (5) humanitarianism (altruism and aesthetics) (Kuh 1993, 1995). The above research findings provided strong evidence on the positive impact of social involvement on development.

\section{Existing studies in Hong Kong and Mainland Chinese contexts}

A small number of studies were conducted on Chinese students' social experiences and development at university. A Hong Kong study on first- and third-year Chinese students' academic/social engagement reported findings similar to the Western studies discussed earlier (Tam 2002). A Mainland Chinese study reported on how social support from teachers, peers, parents and friends was related to freshmen's coping strategies and adjustment to the university environment (Tao et al. 2000).

Two Hong Kong studies reported on how the Chinese students from non-mainstream groups experienced challenges in social life at university. In one of the studies, lack of opportunities for interaction with teachers and peers obstructed the adult part-time students' establishment of a sense of belonging to the learning environment (Kember et al. 2001). In the other study, Lam (2006) found that the Mainland Chinese students encountered difficulties in social interactions during class time because of their perceived differences from local peers in terms of place of origin, language, interests, behaviours and academic abilities.

\section{Summary}

The above analysis of theories and empirical studies points to the significance of students' active social involvement at 
university for their development, especially during their initial year of undergraduate education. Effective social involvement entails students playing a proactive role in making judicious choices and decisions about their social experiences, and establishing a sense of congruence with sub-cultures of communities of university. Research evidence also suggests that social involvement and integration are as important and challenging for Chinese students in Confucian societies as they are for students in Western contexts.

In investigating Chinese and other Asian students' social involvement and development, it would be important to pay attention to the wider social-cultural context in which the students experience social involvement. It is thus critical to view the student culture in connection with the broader Confucian culture when considering its impact on students' social involvement and development.

\section{Methodology}

The collection and analysis of focus group data were guided by the phenomenological perspective (Husserl 1967; Patton 1990). In this tradition, the purpose of inquiry is to describe and understand the essence and structure of things - the social phenomena in the life world. The only reliable source of knowledge is the perceptions of actors who directly experience the phenomenon being studied. This is based on the concept of intentionality, which suggests that human consciousness is always conscious of something (i.e. human knowledge is relational by nature) (Husserl, 1967). Thus, we grounded our understanding of the Chinese students' social involvement and development at university in their firstperson perception. Such understanding was obtained through generating detailed description about the Chinese students' relevant experiences and perceptions (Patton, 1990; Wimpenny and Gass 2000). To serve this end, the selection of participants was purposeful.

Since the primary task of the phenomenology inquiry is to gain access to research participants' experiences, the trustworthiness of findings would rest on the researcher's ability to elicit the participants' detailed account and conceptions about their experiences, which should not be affected by the researcher's own opinions (Goulding 2005; Patton, 1990). In conducting this study, we paid attention to putting aside our own presuppositions about social involvement at university when approaching the participants and interpreting the data. To ensure that the findings are dependable and to assist the readers' judgment of the potential appropriateness the findings to other contexts, we provide below a detailed account of the data collection and analysis procedures.

\section{Data collection}

We chose focus groups as the method for collecting the qualitative data regarding the Chinese students' social experiences and relevant development, since it afforded us with the effectiveness of reaching multiple participants at a time and generating a wide range of student experiences and perceptions (Morgan 1996).

The groups were kept small in size, with 4-6 students from the same faculty in each group. The small group size and students' similar disciplinary background in each group helped maintaining an informal social atmosphere, which encouraged the students' exchange of views and experiences (Sim 1998).

With the use of 10 groups, we were able to collect data on a range of student experiences and perceptions, which helped in countering the negative effects of focus groups (Morgan 1996). Such negative group effects might include one-sided views and overstated agreement on the topic of discussion, which might result from the group conforming to the view of one or two dominant members in the group.

In their focus group, students were asked about their involvement in out-of-class experiences during their first year at the university and how the social involvement impacted on their development and learning. Other questions asked were related to their induction into the academic disciplines, which is addressed in a separate paper.

\section{Participants}

Forty-two Chinese students $($ male $=22$, female $=20)$ from different faculties were involved in the focus groups. All of them were traditional-age 2006 entrants and had just commenced their second year of undergraduate study at the time of data collection. They were recruited from respondents of an institutional survey, in which they indicated willingness to participate in further research. Among them, there were 32 local students, two overseas student and seven Mainland students.

Although the university uses English as the language of instruction, we decided to use Chinese in the focus groups to create a more relaxing atmosphere. Since all the students were able to understand Cantonese (the Chinese dialect spoken in Hong Kong), the focus groups were conducted mainly in Cantonese, though five Mainland Chinese students used Putonghua (Mandarin) in their discussion. All focus groups were transcribed verbatim in English. Possible errors in translation from Chinese into English were eliminated through careful comparison between the transcripts and the notes taken at the focus groups. 
Student communities at the university

The student communities include residential halls, sports (ball games, swimming, etc.) and cultural (dance, choir, magic, etc.) societies/clubs, student academic and nonacademic media (journals, magazines, radio and television stations) and academic associations connected to specific disciplines. Each student community is governed by members of the executive committee, who are student leaders called 'office-bearers'. Positions for office-bearers included the chair person/president, finance secretary, public relations officer, professional development officer, etc. The office-bearers are annually elected by members and autonomously decide on the mission, objectives, strategies, activities/projects and other matters of their community.

Data analysis

Data analysis followed a process described by Patton (1990; see also Goulding 2005), in which the researcher (a) makes explicit his or her presuppositions (personal views, background knowledge and ideas gained from reviewing the literature) regarding the phenomenon to be bracketed; (b) treats all elements and perspectives with equal weight and arranges the data into meaningful clusters; (c) identifies invariant themes within the data by viewing the data from varied perspectives; (d) describes each theme on the basis of invariant themes; (e) describes the essence and structure of the experiences.

To facilitate the process of extracting themes, an overview grid was used, which summarised the main similarities and differences of data from different focus groups (Knodel 1993).

\section{Results}

Influence of the student culture on the Chinese students' out-of-class experiences

The majority $(n=34)$ of the 42 students reported having participated in out-of-class social activities during their freshman year at the university in question. These included activities organised by the student communities in the campus, offices and departments of the university, and youth associations outside the campus. Only eight students were not involved in such activities.

\section{'Living in a hall and serving as an office-bearer'}

For the majority $(n=30)$ of the 42 students, 'living in a hall and serving as an office-bearer' captured the kinds of activities available in their student communities. They reported regular and intensive involvement in social activities organised by the student communities in the campus, including students' residential halls, student societies/clubs, to which they were affiliated.

Among the 19 hall members, two were office-bearers (students holding positions in the executive committee of a residential hall or student society/club) in their hall/floor, and six played in hall/floor sports or cultural teams. Among the 23 members of student societies/clubs, 18 were officebearers, and five were regular members. Eleven students were affiliated to both a student society/club and a hall.

The student culture in their student communities was described as a unique tradition of the university that directed their involvement in social activities in the campus:

I feel that the culture of 'living in a hall and serving as an office bearer' is unique to this university. There is a kind of spirit of our culture that you cannot find in other universities.

In our university, the culture of 'living in a hall and serving as an office bearer' is much stronger than in other universities. Therefore, we can have achievement in different ways in our university.

The hall and/or student society/club expected the students to become actively engaged in out-of-class activities, especially during their freshman year. As two students mentioned:

In Year 1, they [hall mates] had high expectation of freshmen to spend more time in participating hall activities. For example, I served during the Information Day to introduce our hall to secondary school students. Also I played in the inter-hall ball games. The non-compulsory inter-floor activities provide us with a pleasant atmosphere... But there is a kind of peer pressure. You feel 'If I don't participate, the others would hate me and I'd get isolated.'

The office-bearers $(n=20)$ in particular had a wide range of responsibilities and activities, which required them to be multi-talented:

My role was leading the members to organise activities. As the Chairman, I also needed to coordinate with external entities such as professors, professional bodies... So I attended different activities. We also made contact with other student associations at the University.

In the television station, I act as the General Director of the Advertisement Department. I am responsible for arranging the schedule of advertisements for other student associations, writing scripts, directing and editing the programmes, and planning events. 
The students also mentioned various reasons for joining the student communities: to try new experiences, to learn new skills, to meet new friends and to serve others:

Last year (her first year at university) I was the class representative, but still I wanted to get involved and obtain the experience in the Society (her academic association). So I did a lot of work for the Society voluntarily...

The two of us (she and another overseas student) became office-bearers together because we wanted to try it out, to see how the culture in the society was like. We were curious about it.

My reason for becoming an office-bearer [in my academic association] was that I wanted to learn more things in terms of working skills. Besides benefiting myself, I could also serve others ...

It was thus evident that the students' social involvement was both a response to the prevailing student culture and a result of realising their own aspirations about the social life at university.

\section{Other social activities at university}

Four students mentioned joining in social activities that were arranged by departments/offices of the university or youth associations outside the campus:

I am not an office bearer inside the campus, but I play Chinese music in $\mathrm{xxx}$ Youth Association. I am responsible for photocopying the scores and liaising with the conductor and others.

When the xxx Office organised Information Day (for prospective students) in my hometown (in Mainland China), I would provide help there.

\section{Summary of students' out-of-class experiences}

It was clear that the culture of 'living in a hall and serving as an office-bearer' prevailed among the students' social communities, giving direction for the majority of them in social involvement during their first year at the university. The student communities provided the students with rich opportunities for out-of-class experiences that were potentially important for whole person growth. The high expectation on first-year students to participate in group activities was a phenomenon unique to the student communities, which reflected the Confucian values of prioritising communal interests above personal preferences and achieving group interests through individual effort (Watkins and Biggs 2001). Involvement in out-of-class experiences was also a conscious choice made by the students, who availed themselves with the diverse opportunities in the student communities to achieve their personal aspirations about university life.

Dimensions of development outcomes from out-of-class experiences

The students reported four dimensions of development outcomes from their social involvement in out-of-class experiences that took place mostly in the student communities of the university. The four dimensions of development outcomes included their social, practical, intellectual and personal competences.

\section{Social competences}

The first dimension of development outcomes was related to the students' social competences, including interpersonal and collaboration skills and new friendships.

The students reported that the daily social encounters in the halls and student societies/clubs helped them learn to communicate effectively with peers in their student communities and to establish new social support networks. A student mentioned how social interactions in the hall helped her to get along with peers with diverse personalities:

There are over 300 hall mates and we are all friends. But this means that there are 300 kinds of personalities among hall mates. To learn how to get along with them is therefore a learning process.

Another student gave an account of how the experience of being an office-bearer enabled her to make new friends:

...After we became office bearers, we learned a lot, and we made a group of very good friends...Having been together for 1 year as fellow office bearers, we know one another's timetable, phone number and everything else; and we go to classes together. At university, the lecture rooms are so large and classmates say 'Bye-bye' the moment the class is over. Being a member of the committee helped us find a high-school feel and establish friendship.

A student who served as an office-bearer noted the need to refine his interpersonal skills for effectively gaining help from others:

It [interpersonal skill] is an important skill for getting help. You should not ask for too much help. If you do, then the person would say, 'Why should I?' Unless she or he is a friend or is very interested in what you ask him or her to do, you should not request help harshly.

The student communities also afforded the students a unique site for developing collaboration and teamwork skills by 
requiring members to establish a strong sense of collective commitment to the communities. A student who lived in a hall explained how they were trained by seniors in the hall's orientation camp to establish collective loyalty to the hall:

There were several programmes in a night and these involved different tasks. For example, one task required a group of students to climb a wall together and make sure everyone would get through. The tasks were meant to unify the group members. At the end of each programme, the freshmen were told [by seniors] of the meaning of the programme...

Similarly, a student affiliated to an off-campus youth association was motivated by a sense of collective commitment in learning collaboration skills:

I play Chinese music in xxx Youth Association...I have been playing music for a long time and this has become my commitment...I feel it enriches my life and it has helped me to learn skills for collaboration. Since we are in an interest group, our performance is free of charge. It depends on members' collaborative contribution to gain achievements.

\section{Practical competences}

By charging students with real responsibilities in authentic tasks, the student communities provided the students with opportunities to develop such practical competences as time management, organisation, leadership, decision making and negotiation.

A student mentioned how engagement in her student society helped her make better use of time.

...I have also learned time-management. In the hall, I can easily spend time in watching television and play, even though I have to study and to get involved in the student society. So it always requires me to make choices...

The two students cited below mentioned that they learned practical knowledge/skills through their role as officebearers:

I am an office bearer...in the Asian xxx Students' Association (a student academic association). I am responsible for organising the exchange programmes for international student exchange...In coordinating these programmes with my faculty, I came to understand how it is being operated.

As the Financial Secretary (of her student academic journal), I would approach my tasks with courage when I phone up the companies and negotiate with them regarding the prices and the advertisements.
A student mentioned how hall life enabled her to make decisions effectively:

Because there are so many activities (available in the hall), I have learned to make sensible choices.

Leadership skills were afforded to both office-bearers and ordinary members. Two students commented on the opportunities at the student communities to become leaders:

I like the culture of the University, since it allows us to take different posts in student societies just like in the real world. This is similar to what we will be faced with when we enter the society-you hold the posts in order to serve others. What I appreciate about the culture is that it helps us to become future leaders. I have learned how to interact with others, how to lead a team and keep up their spirit.

Leadership role was often taken by ordinary members as well:

I have not lived in a hall or served as an office bearer, but each year during the Open Day, I have taken up the role of a coordinator...I gathered fellow students to discuss the events and allocate tasks...As we have entered our field of study and we like it, we have the responsibility to promote it [to prospective students].

\section{Intellectual competences}

Maintaining an open mind to different views and making independent judgments constituted the intellectual dimension of the students' development outcomes from social involvement. The students reported how participation in out-of-class activities put them into contact with peers from diverse backgrounds with different values and different approaches to tasks.

A student reflected how being an office-bearer taught her to tolerate alternative opinions:

We were often criticised by other members in the Society...This is like what you would do after entering the society: when you hear people's comments, you either accept their criticisms, or politely listen to them.

Two students mentioned how encounters with people holding different perspectives in their student communities facilitated them to become independent in making judgements:

Through organising the events [in my Society], I have realised that different people have different perspectives. So it is important to form my own judgment. For example, when the director of my association 
discussed issues with me, I would analyse the issue as an objective observer and give my own opinions.We are provided with different values and opinions by our hall, student society, our professors and families. Although we hear a lot of different voices, no one tells us who is right and who is wrong. We have to judge for ourselves according to our own ideas. This helps us establish our own system of values.

\section{Personal competences}

The last dimension of the students' development outcomes from social involvement was their personal competences that included the sense of self-responsibility and self-confidence. This dimension marked the students' transition from youth towards adulthood, wherein selfresponsibility and self-confidence were regarded as the distinctive characteristics of themselves as maturing individuals.

A student mentioned that taking part in hall orientation activities made him realise the importance of having a serious attitude towards tasks:

I like the orientation camp (a hall orientation programme for new hall members). There were a lot of meaningful activities, which taught us to become more mature as a university student ...I learned the attitude towards things-whatever you do, you should put your effort in it.

Another student commented that engagement in social activities in student communities required students to take self-responsibility and develop self-confidence:

At university, you have to decide for yourself when to study and take part in student activities, and how to play, to rest and to get along with others. You have to learn to make people feel confident in you. This is different from what we experienced at school.

The above analysis indicates that it was both the specific student culture of the student communities and the general institutional environment that provided students with the kind of attitudes and opportunities associated with taking responsibilities.

\section{Summary of the students' development outcomes from out-of-class experiences}

The above analysis provides clear evidence that by taking part in out-of-class activities organised mainly by the student communities, the students achieved outcomes in four dimensions that encompassed social, practical, intellectual and personal development.
The unique student culture that the students experienced left a distinct mark in all these dimensions of development outcomes. While prescribing the rules, norms, values and patterns of behaviours that tended to restrict the students' social activities in certain ways (e.g. participation in such group activities as inter-hall competitions), the student communities also afforded a variety of choices both in terms of activities to take part and perspectives to adopt, which encouraged open-mindedness and agency in social involvement.

\section{Discussion}

The students interpreted 'living in a hall and servicing as an office-bearer' as a student culture unique to the university. It encouraged their participation in social activities and directed their expense of energy and time. It thus appeared to be a strong sub-culture at the university (Tinto 1993) and an integral part of the overall campus culture and institutional climate (Kuh and Hall 1993; Stern 1970). That the majority of the students chose to become members of at least one student community was suggestive of their sense of congruence with the student culture.

The student culture enabled the students to take up different roles and responsibilities, and develop competences and friendships, which coincided with their aspirations for university life. Thus, social involvement was both their response to the student culture and a conscious personal decision, which meant that they did play a proactive role in their own education (Dewey 1938; McInnis et al. 1995). This was especially true with the office-bearers.

Being rooted in the Confucian tradition, the student culture mirrored the Confucian values, such as the expectations (through instruction by older members) of individuals to comply with the student communities' rules and to contribute to collective goals by participating in group activities. This to some extent restricted students' free choices among out-of-class experiences.

On the other hand, the out-of-class experiences promoted by the student culture corresponded to the optimal social experiences for student development identified in Western contexts (Astin, 1985; Kuh 1993, 1995; Krause and Hartley 2005). The students reported development outcomes from social involvement in four dimensions: (1) the social competences of interpersonal and collaboration skills and new friendships; (2) the practical competences of time management, organisation, negotiation, decision making and leadership; (3) the intellectual competences of open-mindedness and independent judgment; and (4) the personal competences of self-responsibility and self-confidence. They also explicitly attributed such outcomes to out-of-class experiences. 


\section{Conclusion}

The findings of this study about the Chinese students' social participation at university as a response to the student culture embedded in Confucian values would contribute to the fields of Asian students' experiences and development in higher education particularly and crosscultural psychology and comparative education more generally. The educational implications of the findings would be useful to academics, student affairs officers and hall wardens/tutors who are responsible for advising students on social, personal and academic issues.

The most significant findings were that the majority of the 42 Chinese students became socially involved during their freshman year both as a response to the prevailing student culture and a conscious choice about university life and that such experiences led to their personal, practical, social and intellectual development. The student culture of the university- 'living in the hall and serving as an officebearer' - was generally conducive to the Chinese students' development. It was a significant and integral part of students' experiences and development as whole persons.

The findings have significant educational implications for promoting whole person development among undergraduate students, including students studying at university in Confucian societies and other contexts where a large number of Chinese and other Asian students are studying as student travellers.

In order to support students' all-round development, students need to be encouraged in active engagement in student communities and in making sensible choices among opportunities for exploring new ideas and new roles in the communities. It would also be desirable to monitor closely how the student culture influences students' social participation and growth.

A critical time for giving support is during the first year of university. This is a period when students may not be fully acquainted with benefits of social involvement and may be overwhelmed by numerous demands by university. Except individual consultations, seminars, workshops and faculty-led social activities would also be viable in advising students in these respects.

Open Access This article is distributed under the terms of the Creative Commons Attribution Noncommercial License which permits any noncommercial use, distribution, and reproduction in any medium, provided the original author(s) and source are credited.

\section{References}

Arboleda, A., Wang, Y., et al. (2003). Predictors of residence hall involvement. Journal of College Student Development, 44, $517-531$
Astin, A. W. (1985). Achieving educational excellence: A critical assessment of priorities and practices in higher education. San Francisco, CA: Jossey-Bass.

Bond, R., \& Smith, P. B. (1996). Culture and conformity: A metaanalysis of studies using Asch's (1952b, 1956) line judgment task. Psychological Bulletin, 119(1), 111-137.

Coates, H., Hillman, K., et al. (2008). Attracting, engaging and retaining: New conversations about learning (Australian student engagement report-Australian survey of student engagement). Carnberwell, Victoria: ACER (The Australian Council of Educational Research)

Dewey, J. (1938). Experience and education. New York: Collier Books.

Goulding, C. (2005). Grounded theory, ethnography and phenomenology: A comparative analysis of three qualitative strategies for marketing research. European Journal of Marketing, 39(3/4), 294-308.

Harvey, L., Drew, S., et al. (2006). The first year experience: A literature review for the Higher Education Academy. York: Higher Education Academy.

Husserl E (1967) Phenomenology and the Crisis of Philosophy. Translated with notes and introduction by Quentin Lauer. New York, Harper and Row Publishers.

Kember, D., \& Gow, L. (1991). A challenge to the anecdotal stereotype of the Asian student. Studies in Higher Education, 16(2), 117-128.

Kember, D., Lee, K., et al. (2001). Cultivating a sense of belonging in part-time students. International Journal of Lifelong Education, 20(4), 326-341.

Knodel, J. (1993). The design and analysis of focus group studies: A practical approach. In D. Morgan (Ed.), Successful focus groups: Advancing the state of the art (pp. 35-50). London: Sage Publications, Inc.

Krause, K., Hartley, R., et al. (2005). The first year experience in Australian universities: Findings from a decade of national studies. Retrieved 10 August 2007, from http://www.griffith.edu. au/centre/gihe/aboutus/klk_publications/FYEReport05.pdf.

Kuh, G. D. (1993). In their own words: What students learn outside the classroom. American Educational Research Journal, 30(2), 277-304.

Kuh, G. D. (1995). The other curriculum: Out-of-class experiences associated with student learning and personal development. Journal of Higher Education, 66, 123-155.

Kuh, G. D., \& Hall, J. E. (1993). Using cultural perspectives in student affairs. In G. D. Kuh, \& M. D. Lanham (Ed.), Cultural perspectives in student affairs work (pp. 1-20). American College Personnel Association.

Lam, M. H. (2006). Reciprocal adjustment by host and sojourning groups: Mainland Chinese students in Hong Kong. In M. Byram \& A. Feng (Eds.), Living and studying abroad: research and practice (pp. 91-107). Clevedon: Multilingual Matters Ltd.

McInnis, C. (2001). Researching the first year experience: Where to from here? Higher Education Research and Development, 20(2), $105-114$.

McInnis, C., James, R., et al. (1995). First year on campus: Diversity in the initial experiences of Australian undergraduates. Canberra: Australian Government Publishing Services.

Morgan, D. (1996). Focus groups. Annual Review of Sociology, 22, $129-152$.

Ng, S. W. (2009). Transformation of students into active and participatory citizens: An exploratory study in Hong Kong. Educational Research for Policy and Practice, 8(3), 181-196.

Pascarella, E. T., \& Terenzini, P. T. (2005). How college affects students: A third decade of research. Indianapolis, IN: JosseyBass. 
Patton, M. Q. (1990). Qualitative evaluation and research methods. London: Sage Publications.

Sim, J. (1998). Collecting and analysing qualitative data: isues raised by the focus group. Methodological issues in nursing research, 28(2), 345-352.

Stern, G. G. (1970). People in context: Measuring person-environment congruence in education and industry. New York: Wiley.

Tam, M. (2002). Measuring the effect of higher education on university students. Quality Assurance in Education, 10(4), 223-228.

Tao, S., Dong, Q., et al. (2000). Social support: Relations to coping and adjustment during the transition to university in the People's Republic of China. Journal of Adolescent Rsearch, 15(1), 123-144.

Tinto, V. (1993). Leaving College: Rethinking the causes and cures of student attrition. Chicago: University of Chicago Press.

UGC. (2010). The 9th Symposium - First Year Experience. Retrieved 16 May 2010, from http://www.cityu.edu.hk/vpsa/334symposium/ symposium.html.
Watkins, D., \& Biggs, J. (1996). The Chinese learner: Cultural, psychological, and contextual influences. Hong Kong: CERC \& ACER.

Watkins, D., \& Biggs, J. (2001). The paradox of the Chinese learning and beyond. In D. Watkins \& J. Biggs (Eds.), Teaching the Chinese learner: Psychological and pedagogical perspectives. Hong Kong: Comparative Education Research Centre, The University of Hong Kong.

Wimpenny, P., \& Gass, J. (2000). Interviewing in phenomenology and grounded theory: Is there a difference? Journal of Advanced Nursing, 31(6), 1485-1492.

Yee, P. L. F. Y. (2001). Competing contexts for developing personal and social education in Hong Kong. Comparative Education, $37(1), 65-87$.

Yorke, M., \& Longden, B. (2007). The first year experience in higher education in the UK. Heslingon, UK: The Higher Education Academy. 